\title{
Rousseau y la idea de comunidad política
}

\author{
JAVIER PEÑA ECHEVERRÍA \\ Universidad de Valladolid
}

En este artículo se toma la noción de comunidad como clave de interpretación de la filosofía política de Rousseau, a la vez que se ilustran con ésta la nostalgia de la comunidad en las sociedades modernas y las diferentes imáge- nes de la comunidad política a las que apela la filosofía contemporánea: la comunidad de la voluntad general, construida deliberativamente, y la comunidad de tradición y pertenencia, arraigada en vinculos afectivos.

\section{Introducción}

La filosofía política de Rousseau se presta, quizá como ninguna otra, a la controversia entre sus intérpretes.' Aun si se acepta la tesis de Cassirer sobre la unidad de fondo del pensamiento rousseauniano, ${ }^{2}$ no es posible pasar por alto el cúmulo de ambigüedades, y hasta contradicciones, de la obra asistemática de este pensador, apasionado y propenso al exceso retórico, y situado además en la encrucijada de una sociedad que, a la vez que celebra la emancipación de los individuos respecto de los vínculos orgánicos tradicionales, añora la solidaridad comunitaria perdida, sustituida por el enfrentamiento entre los sujetos egoístas que concurren en el mercado.

Sin embargo, las carencias, tensiones y aporias que es posible detectar en el pensamiento de Rousseau resultan particularmente interesantes para los propósitos de este trabajo. En él se toma como eje la noción de comunidad, considerándola como idea clave para la interpretación del proyecto teórico-político de Rousseau; y las dificultades y vacilaciones que se aprecian en la concepción rousseauniana de la comunidad ilustran admirablemente aquellas a las que se enfrentan la teoría y la práctica política contemporáneas en este punto.

Pues es patente que la aspiración a una sociedad que pueda ser considerada como una comunidad está ampliamente extendida en las atomizadas sociedades postindustriales; pero es cierto también que el mismo término puede designar contenidos diferentes. Podemos mentar con la palabra "comunidad", algo emparentado con la Gemeinschaft de Tönnies: una unidad solidaria "natural", ligada por lazos de sangre, tierra o cultura, con una intensa tonalidad afectiva; o bien la idea de una sociedad (o proyecto 
de ella) caracterizada por la determinación conjunta y solidaria de un interés común, que supera la mera coexistencia de intereses privados.

En ambos casos la noción de comunidad se relaciona negativamente con la de individualismo (aunque no necesariamente con la de individuo), y enfatiza lo común, la integración y la solidaridad, como aspectos básicos de la relación social. Pero mientras la primera acepción de "comunidad" subraya la referencia a la tradición y la pertenencia a un contexto previo, la vinculación al pasado -como ocurre en las propuestas comunitaristas de corte neoaristotélico o neohegeliano-, ${ }^{3}$ la segunda pone el acento en la construcción deliberada (en los dos sentidos de esta palabra) de una sociedad solidaria, "más allá del contrato social» - para decirlo con Muguerza. ${ }^{4}$ Se orienta, por tanto, a la construcción del futuro.

Pues bien, ambas representaciones de la comunidad política coexisten en la obra de Rousseau. Y una reflexión sobre la posibilidad, deseabilidad, límites y condiciones de una forma de vida comunitaria en las sociedades actuales bien pudiera pasar por una relectura de este pensador.

\section{La critica de la sociedad moderna}

Cabe considerar, desde la perspectiva adoptada, a la pars destruens de la teoría política rousseauniana (la de los Discursos, junto con algunas cartas y fragmentos) como una crítica de la sociedad moderna, cuyo eje sería precisamente la denuncia de la ausencia de la dimensión comunitaria, y de su sustitución por el «individualismo posesivo» de una sociedad en la que los fuertes crecen a costa de los débiles, y todos son víctimas de la inagotable multiplicación de necesidades y deseos.

Una crítica no exenta de ambigüedad. A veces Rousseau parece abandonarse a la nostalgia de los vínculos fraternales de las sociedades precapitalistas, de las pequeñas comunidades rurales, y soñar con un imposible retorno al pasado, o incluso a un tiempo mítico anterior a toda sociedad. ${ }^{5}$ Y se diría que la crítica alcanza, no ya a la sociedad moderna, sino a la sociedad tout court, y que Rousseau lamenta, no sólo la emergencia de] individualismo, sino la de la propia individualidad.

Pero lo cierto es que la crítica rousseauniana va unida a una propuesta constructiva - la de El controto social-; y en todo caso, lo que nos importa es el fruto del ejercicio crítico: en los "Discursos" - de forma abrupta y desmesurada en el primero, con mayor rigor analítico en el segundo-, Rousseau expone la genealogía de la sociedad moderna: en parte con un moralismo simplificador, pero en parte también con una perspicacia que le permite anticipar las críticas hegeliana y marxiana de la sociedad civil.

La exposición de los Discursos ha de ser considezada en el contexto de la emergencia de la individualidad que caracteriza la constitución de la sociedad moderna. ${ }^{6} \mathrm{~A}$ lo largo de un complejo y dilatado proceso de transforma- 
ción (de cuyos factores y vicisitudes no podemos ocuparnos aquí), las comunidades premodernas son sustituidas por sociedades individualistas, cuyo espíritu queda reflejado en las representaciones del mercado y del contrato social: la sociedad es un artificio para la coexistencia y equilibrio de intereses privados previos en competencia, potencialmente enfrentados entre sí.

Sin duda alguna, este proceso arroja resultados positivos. La modernidad trajo consigo, no sólo el incremento de bienestar generado por el desarrollo de las fuerzas productivas - como destaco el propio Marx-, sino también el desarrollo de una subjetividad liberada de la autoridad y de la tradición, que afirma su autonomía tanto en el plano de la conciencia como en las relaciones sociales.

Estos rasgos positivos alentaron el autocomplacido optimismo ilustrado. Pero el proceso tenía también sombras, y Rousseau tomó a su cargo la tarea de desvelar la cara negativa oculta por el brillo de las Luces. Niega el presupuesto último inspirador del proyecto enciclopedista: la convergencia de progreso material y progreso moral. Dicho de otro modo: niega que el desarrollo de la civilización moderna haya supuesto la perfección de la condición humana. Frente a esta tesis, el Discurso sobre las ciencias y las artes sostiene, provocador, que "nuestras almas se han corrompido a medida que nuestras ciencias y nuestras artes han avanzado hacia la perfección» (OC, III, 9). ${ }^{7}$ El resultado de la civilización, desde el punto de vista moral, es la alienación del propio ser en el aparecer, el artificio y la máscara de la cortesía, que ocultan el conflicto de intereses y reflejan la dependencia de la opinión ajena.

El autor denuncia la mercantilización de la vida pública — "Los antiguos políticos hablaban sin cesar de costumbres y de virtud; los nuestros no hablan más que de comercio y de dineron (OC, III, 19)-; la multiplicación de deseos y necesidades, en una dinámica inagotable; la conversión de lo superfluo en eje de la actividad económica. (El lujo, cuya función como estímulo de la producción es ponderada por contemporáneos como Voltai$\mathrm{re}^{8}$ es a su juicio un claro exponente de una sociedad desequilibrada.)

Esta crítica moral de la sociedad moderna tiene uno de sus puntos de apoyo en la imagen idealizada de la comunidad antigua, en los modelos de Esparta y de la Roma republicana. Idealizadas a través de la lectura de Platón y de Plutarco, ${ }^{9}$ Esparta y Roma son vistas como ejemplos de una comunidad moral en la que los intereses individuales están fundidos en el público, y cuyos valores dominantes son el patriotismo, la austeridad, y el amor a la libertad colectiva, a diferencia de la ambición, artificiosidad e individualismo de las sociedades modernas. Más allá de la evocación nostálgica, la mirada a la Antiguiedad sirve para poner de relieve las carencias y lacras del presente.

No obstante, es el concepto de hombre natural, eje del Discurso sobre el origen y los fundamentos de la desigualdad entre los hombres, el que posibilita el desarrollo y profundización en la crítica. Pues dicha obra consiste en una 
genealogia de la "mala socialización» del hombre moderno. A diferencia de los téoricos iusnaturalistas anteriores, Rousseau se remite al «estado de naturaleza», no para extraer de él una justificación de la sociedad actual -mostrándola como solución razonable, dadas las condiciones del estado de naturaleza, y en último término de la naturaleza humana-, sino para hacer ver que, lejos de ser resultado necesario de dicha naturaleza, es el producto histórico de la perversión de la condición original del hombre. Y lleva a cabo una reconstrucción hipotética de la historia de esa sociedad civil, tomando como punto de partida la imagen del hombre tal como sería sin las adherencias del proceso de civilización. Historia que, como trataré de mostrar mediante la referencia a algunos lugares del Discurso sobre la desigualdad, corre paralela a la del desarrollo del individualismo y sus consecuencias.

La imagen de un «hombre natural» aislado, autárquico, y sin apenas relaciones sociales, parece sugerir, a primera vista, un enfoque individualista. ${ }^{10}$ Pero creo que esta interpretación no es correcta, porque el hombre natural rousseauniano no se ha desarrollado aún como sujeto. No se han despertado sus facultades intelectuales -y por tanto, tampoco sus deseos-; probablemente, apunta Rousseau, no reconoce individualmente a sus semejantes (cf. OC, III, 160). Lejos, pues, de ser un individuo independiente, solo existe en cuanto miembro de la comunidad a la que pertenece, la comunidad de la Naturaleza, en cuyo seno materno transcurre armónicamente su existencia. El precio que paga por estar a resguardo de los males de la civilización es la carencia de subjetividad: su vida transcurre por los cauces prefijados del equilibrio natural, de un orden previamente dado. (Su posición es análoga, a este respecto, a la de los miembros de las comunidades tradicionales,)

La conexion entre emergencia de la individualidad y conflicto se hace patente en el retrato moral del hombre natural. Uno de los tópicos más celebrados de Rousseau es el que se refiere a la "bondad natural" del hombre. Pero el filósofo ginebrino advierte que el hombre natural no es susceptible, en rigor, de calificación moral: "[...] no teniendo los hombres en ese estado ninguna clase de relación moral entre sí, ni deberes conocidos, no podían ser buenos ni malos, y no tenían ni vicios ni virtudes" (OC, III, 152). La moralidad presupone sujetos autoconscientes y relaciones sociales. El hombre natural es "bueno" sólo en el sentido de que no está inexorablemente atado a la competencia y a la «voluntad de poder»: si Rousseau utiliza la expresión mencionada, es para sostener que el homo oeconomicus de la sociedad civilizada moderna, que trata de maximizar su utilidad frente a, y a costa de, los demás, no es el hombre.

En efecto, si el hombre natural está movido por el deseo de autoconservación, como afirma Hobbes, tal deseo no implica por sí mismo antagonismo. Es preciso distinguir, advierte Rousseau, entre amour de soi y amour propre. El primero se da en cualquier animal en cuanto ser vivo; y 
no es propiamente egoísta, porque es anterior a la constitución de la subjetividad misma. El segundo, en cambio, es sun sentimiento relativo, ficticio y nacido en la sociedad, que lleva a cada individuo a hacer más caso de sí que de cualquier otro", que «inspira a los hombres todos los males que se hacen mutuamente, y que es la verdadera fuente del honor" (OC, III, 219). El amor propio corresponde a la individualidad desarrollada, a la conciencia de sí y la autoestima, a la vez alimentada y obstaculizada por los demás; por eso es competitivo, y potencialmente conflictivo.

Es la ausencia de la pitié, de la conmiseración espontánea ante el mal ajeno que experimenta el hombre natural, lo que define al amor propio. En el célebre pasaje sobre la insensibilidad del filósofo del Discurso sobre la desigualdad, Rousseau observa cómo el desarrollo de la racionalidad y de la reflexión va parejo con la indiferencia ante el destino ajeno y el desarrollo del amor propio. Individualidad y reflexión aparecen ligadas a insolidaridad y conflicto, mientras que los impulsos espontáneos del hombre natural se vinculan a la piedad y a la armonía.

¿Sería posible la conjunción de individualidad y comunidad? En la sociogénesis descrita por el Discurso sobre la desigualdad, ello ocurre sólo en la situación efímera de la sociedad patriarcal de la "juventud del mundo", a medio camino «entre la indolencia del estado primitivo y la impetuosa actividad de nuestro amor propion (OC, II, 171). En ella, la integración social se asienta en la identidad de la forma de vida y en las condiciones materiales de existencia, que hacen posible la cooperación sin dependencia y la ausencia de conflictos derivados de la escasez. Se conservan aún la libertad e igualdad del estado de naturaleza, y se goza de las ventajas del desarrollo racional: la belleza moral y la fiesta." Aun si la descripción rousseauniana de tal sociedad no es tan idílica como sugiere la apelación tópica al "buen salvaje», refleja ciertamente la nostalgia de una comunidad fraternal, de una vida sencilla y solidaria.

Pero este precario equilibrio queda roto por la modificación de dichas condiciones materiales: la aparición de la división del trabajo y de la propiedad privada - consecuencia de las de la metalurgia y la agricultura- determinan la constitución de la sociedad civil, descrita por Rousseau con rasgos hobbesianos. La evolución social —explotación intensiva de la tierra, intercambio, propiedad exclusiva de algunos, diferencia de talentos y de rendimientos- determina el surgimiento de la desigualdad social y la desaparición del vínculo comunitario, sustituido no sólo por la competencia, sino por la dominación. Y la escisión material se refuerza y prolonga en la social:

Finalmente, la ambición devoradora, el ansia de aumentar su fortuna relativa, menos por auténtica necesidad que por ponerse por encima de los demás, inspiran a todos los hombres una negra inclinación a perjudicarse mutuamente, una envidia sccreta, tanto más peligrosa cuanto que, para hacer su jugada con mayor seguri- 
dad, adopta a menudo la máscara de la benevolencia; en una palabra, competencia y rivalidad por un lado, oposición de intereses por otro, y siempre el oculto deseo de lograr un beneficio a costa del otro: todos estos males son el primer efecto de la propiedad y el cortejo inseparable de la sociedad naciente [OC, III, 175].

Así, del desarrollo del amor propio individualista, impulsado por el progreso material, resulta una sociedad antagónica, de individuos enfrentados e insatisfechos. $Y$ para eludir la guerra de todos contra todos, la solución aparente es el pacto social, formulado en términos lockeanos: se trata de agrupar las fuerzas de los contratantes, y de someterse a un orden común, para garantizar la seguridad personal y el disfrute de la propiedad (OC, III, 177).

Pero en realidad, denuncia Rousseau, es un pacto fraudulento: tras la igualdad formal se enmascara la desigualdad real (respecto a la propiedad), que el pacto no hace sino convalidar. Aun si el filósofo ginebrino no ha sabido entender la irreversible evolución de la economía capitalista - por lo que sus propuestas en materia económica resultan arcaizantes-, no cabe duda de que tiene una clara intuición de la naturaleza conflictiva de la sociedad modema, y de las raíces cconómicas de la misma, como han señalado los estudiosos marxistas de Rousseau. ${ }^{12}$ Éste ha mostrado que una sociedad constituida sobre el pacto social liberal no suprime el antagonismo del estado de guerra; sólo lo enmascara.

¿Qué solución cabe, a la vista de este diagnóstico? Una aparente salida seria el retomo al estado de naturaleza o, cuando menos, el apartamiento de la sociedad. Rousseau se siente tentado de abandonar una sociedad que le parece artificiosa e inmoral: sería el repliegue del "alma bella» ante la insuficiencia de la política. ${ }^{13}$ Pero en todo caso es consciente de que para la Humanidad es imposible retroceder; aunque sea necesario mirar hacia atrás, para comprender la magnitud de la pérdida, no cabe volver hacia atrús: el hombre actual ha adquirido una "segunda naturaleza" social de la que ya no puede desprenderse..$^{14}$ No es posible retornar al seno de la comunidad natural.

Un segundo camino sería la restauración de la comunidad antigua de la tradición espartana y romana. $Y$ en la obra de Rousseau resuena el eco de la república clásica idealizada; late el deseo de revivir el ethos clásico en la sociedad modema. Pero Rousseau no es sólo un crítico romántico de la civilización, o un admirador nostálgico de los antiguos. Siquiera sea a regañadientes, acepta la irreversibilidad del desarrollo de la moderna sociedad civil. Prueba de ello es su propuesta de un nuevo contrato social, que arranca precisamente del reconocimiento del resultado del proceso histórico.

\section{La comunidad de la voluntad general}

A mi juicio, la propuesta del Contrato social puede interpretarse como la de una comunidad política fundada en el acuerdo de sujetos autónomos y 
racionales, en condiciones de libertad, igualdad y reciprocidad, respecto a su interés común. De tal acuerdo resultaría una sociedad caracterizada por fuertes vínculos de participación y solidaridad, al tiempo que asentada sobre una individualidad desarrollada (lejos de la mera fusión en el Todo colectivo).

Es decir, Rousseau apunta la hipótesis de otra individualidad. Si hasta ahora el individuo se ha desarrollado frente a los otros, competidores en el mercado, cabe pensar en otro sujeto, un yo-con-los-otros, solidario en lugar de individualista. Y a la vez, se esboza otra comunidad, constituida no por disolución de los individuos, sino por el entretejimiento de sujetos autónomos.

Esta interpretación -que trataré de desarrollar en lo que sigue-, presupone, en primer lugar, la continuidad entre la parte crítica de la obra política de Rousseau y el Contrato social. Es decir, que la crítica del Discurso sobre la desigualdad no se refiere a la sociedad en general, sino a la sociedad tal como se ha desarrollado histónicamente; y que lo que el Contrato social propone es una refundación de la sociedad sobre principios que la hagan legítima. Tal es la tesis sostenida por Kant en su escrito Probable inicio de la historia humana, ${ }^{15}$ hoy comúnmente aceptada aun por quienes piensan que es un ensayo fallido, al pretender conjugar elementos contradictorios (Villaverde), o una elegia política, que describe la sociedad que podría haber sido si el proceso histórico hubiera sido otro (Philonenko). ${ }^{16}$

En segundo lugar, la interpretación no implica que Rousseau proyectara conscientemente tal objetivo en los términos en que aquí se ha descrito; y menos aún que lograra crear, siquiera sobre el papel, un modelo de comunidad política que conjugue autonomía e interdependencia. De hecho, se le ha tachado tanto de individualista-incapaz de superar las premisas contractualistas de su proyecto-, como de totalitario, por acentuar en exceso la dimensión colectiva.

Podemos ahora considerar en qué medida alcanzan dichas críticas a la tentativa rousseauniana de construcción contractualista de la comunidad política.

Para empezar, no cabe duda de que Rousseau forma parte de la tradición contractualista, y de que ésta se asienta en presupuestos individualistas: la sociedad política resulta del acuerdo de individuos preexistentes e independientes. Por eso fracasa el autor del Contrato, piensa Hegel, en su pretensión de construir una voluntad general que supere el particularismo. ${ }^{17}$ Y por eso está condenado, según Della Volpe, a la abstracción: parte de una independencia originaria extrahistorica, mítica, que hace inviable la fundamentación de la sociedad política ${ }^{18}$

Para valorar estas críticas conviene situar la opción contractualista de Rousseau en su contexto histórico y, sobre todo, atender a las características específicas del contrato rousseauniano. 
Ante todo, ha de recordarse que la teoria contractualista de Rousseau supone un paso adelante respecto a la legitimación teológica o iusnaturalista del poder (como el propio Hegel reconoce). Lejos de apelar a la voluntad de Dios o a "la naturaleza de las cosas", el contractualismo rousseauniano funda la legitimidad del orden social en la voluntad de los ciudadanos que lo constituyen: sostiene una tesis convencionalista respecto al origen del poder.

Según Habermas, con Rousseau se inicia la sustitución de la legitimación naturalista por una legitimación procedimental: la validez de las normas se establece por las condiciones formales de su justificación; ${ }^{19}$ es decir, se funda políticamente. Es cierto que la posición rousseauniana no es tan nítida como quizá fuera deseable, y que no faltan pasajes que permitan hablar a valedores del iusnaturalismo de Rousseau, como Derathé, de la subsistencia de un "derecho natural razonado" en el Contrato social: ${ }^{20}$ pero parece claro que el ginebrino afima, frente al recurso al "orden natural» para sostener la situación efectiva de desigualdad social y política, que todo derecho se establece por la voluntad de los ciudadanos asociados. $\mathrm{Si}$ reconoce que «lo que está bien y conforme al orden es tal por la naturaleza de las cosas e independientemente de las convenciones humanas», advierte a renglón seguido que «toda justicia viene de Dios, él es su única fuente; pero si supiéramos recibirla de tan alto no necesitaríamos gobierno ni leyes»; de manera que "son por consiguiente necesarias convenciones y leyes para unir los derechos y los deberes y remitir la justicia a su objeto» (CS, II, 6; OC, III, 378). Al tiempo que apela a un principio de justicia no convencional, sostiene que sólo mediante la deliberación convencional es posible definirlo y concretarlo.

Por otra parte, hay que advertir que Rousseau no propone un contrato cualquiera, sino un contrato legítimo. Es decir,-que conjugue sociedad y libertad. En las condiciones actuales de la humanidad resulta inprescindible la vinculación a un orden político; pero eso no implica necesariamente un pacto de sumisión (como creyeron Grocio, Hobbes, o Pufendorf), la pérdida de la libertad y la dependencia de un poder ajeno. Es posible hallar "una forma de asociación que proteja con toda la fuerza común la persona y los bienes de cada asociado, y por la cual, uniéndose cada uno a todos, no obedezca sin embargo más que a sí mismo y quede tan libre como antes" (OC, III, 60).

Y la fórmula es "la alienación de cada asociado con todos sus derechos a toda la comunidad" (ibidem), la puesta en común de sus personas y capacidades bajo la dirección de la voluntad general. Un contrato, pues, muy particular, ya que no consiste en una transacción entre dos partes que intercambian bienes o posiciones, y en la que cada uno de los contratantes es término de la relación, sino en un acuerdo de integración en una comunidad, que culmina en la desaparición de los particulares en tanto 
que meramente particulares: el bourgeois se convierte en citoyen. Paradójicamente, la conclusión del contrato es la supresión de sus premisas individualistas.

El proyecto rousseauniano de comunidad pretende, en definitiva, trascender la antítesis individualismo-colectivismo, tomando como eje el concepto de voluntad general. Creo que puede decirse que Rousseau bosqueja (aun si no del todo explícitamente) un modelo de comunidad, el de la comunidad de la voluntad general, caracterizado por los siguientes rasgos:

1) Es una comunidad de sujetos libres. $Y$ aquí libertad significa autonomia: que «los sujetos no obedecen a nadie, sino a su propia voluntad" (CS, II, 4; OC, III, 375). Esto es posible porque los ciudadanos obedecen a normas que resultan de la autodeterminación colectiva, normas que se han dado a sí mismos. Una comunidad de sujetos autónomos ha de ser una comunidad democrática (y viceversa).

2) Los sujetos están en una posición de igualdad: "todos se comprometen bajo las mismas condiciones y deben gozar de los mismos derechos» (CS, II, 4; OC, III, 374). Sólo la igualdad hace posible la reciprocidad que establece la fórmula del contrato social, y la superación de la contradicción entre interés particular e interés general: puesto que lo que cada uno quiera para sí mismo ha de quererlo para los demás, la determinación colectiva se orienta al interés común.

Es bien conocida la crítica de Marx en La cuestión judia, según la cual la libertad e igualdad proclamadas en el Contrato social se reducen a la esfera politico-jurídica, formal, sin alcanzar al plano material. Pero lo cierto es que Rousseau es bien consciente de que no puede haber libertad sin igualdad. Como hemos visto, su crítica al pacto social histórico se cifra precisamente en la denuncia del encubrimiento de la desigualdad material bajo la igualdad formal; y la lógica misma de la propuesta del Contrato social exige una simetría plena en el compromiso constituyente para salvar la autonomía de los sujetos.

Prueba de ello son las referencias de Rousseau al tema de la propiedad. En el Contrato social, el derecho de propiedad aparece subordinado a la comunidad, y limitado por un criterio de igualación: "que ningún ciudadano sea lo bastante opulento para poder comprar a otro, ni nadie tan pobre como para estar obligado a venderse" (CS, II, 11; OC, III, 391-392). Considera que la propiedad es condición necesaria de autonomía - de la capacidad de disponer de sí mismo-, al tiempo que cree necesario evitar niveles de desigualdad que hagan imposible la comunidad que proyecta. Las propuestas económicas de Rousseau en el Proyecto de Constitución para Córcega pueden ser tachadas de ingenuas; pero confirman que pone la igualdad real como condición de la comunidad.

3) La voluntad general requiere universalidad. En primer lugar, en cuanto al sujeto: "Para que una voluntad sea general no siempre es necesa- 
rio que sea unánime, pero es necesario que todas las voces sean tenidas en cuentas (OC, III, 369). Pero sobre todo en cuanto al objeto. $\mathrm{Y}$ esto en una doble dimension: en cuanto se aplica a todos, y en cuanto expresa un interés común. De la voluntad general resultan normas aplicables a cualquier miembro de la comunidad, y no referidas a intereses particulares. La bondad de los fines de la acción política se mide por su universalizabilidad, su capacidad de ser auténticamente comunes.

4) La voluntad general ha de expresarse por medio de una deliberación pública, ${ }^{21}$ que no puede ser sustituida ni siquiera por el dictamen de un experto como el Legislador. Tal deliberación ha de ser ejercida sobre la base de una informacion suficiente y en condiciones que garanticen la independencia en la emisión de opiniones: requisitos que expresan la racionalidad que ha de presidir las deliberaciones definitorias de la voluntad general.

El resultado de la conjunción de estas condiciones es una comunidad democrática, en la que se produce la síntesis entre la autonomía individual - pues el soberano "no está formado más que por los particulares que lo componen" (CS, I, 7)-y la dimensión comunitaria. Es decir, del hombre y el ciudadano. Pero no mediante la anulación de la particularidad, sino por la instauración de la intersubjetividad, la codeterminación de sujetos autónomos.

Este modelo de comunidad inspiró sin duda la idea kantiana del "reino de los fines»; y, en nuestros días, la teoría de la democracia de Habermas, quien en Problemas de legitimación en el capitalismo tardio, apela a una voluntad racional estrechamente emparentada con la voluntad general rousseauniana:

Podemos llamar "racional" a la voluntad formada discursivamente, porque las propiedades formales del discurso y de la situación de deliberación garantizan de manera suficiente que puede alcanzarse un consenso sólo mediante intereses generalizables, interprctados adecuadamente, es decir necesidades compartidas comunicartivamente. ${ }^{22}$

La objeción más común a la filosofia política de Rousseau se dirige, sin embargo, contra la supuesta tendencia totalitaria de su pensamiento. ${ }^{23}$ Desde este flanco, se reprocha a Rousseau la absorción de la dimensión privada por la pública. El Estado, institucionalización de la voluntad general, define las metas y los modos apropiados de conducta, de manera que a quien rehúse obedecer a la voluntad general «se le forzará a ser libre» (CS, I, 7): la concepción rousseauniana no sólo no admitiría la disidencia, sino que identificaría la libertad con la coincidencia con la definición del bien establecida por el poder.

Llegados a este punto, es preciso recordar que la concepción de la 
libertad mantenida por Rousseau no es "negativa», según la terminología de Berlin, ${ }^{24}$ sino "positivan: se trata de que los sujetos sean dueños de su destino, que participen en la determinación de sus vidas. Rousseau considera la libertad, por tanto, desde una perspectiva comunitaria, en la que la libertad de cada uno está positivamente vinculada a la de todos. La libertad sólo puede ser real en condiciones tales que todos sean simultáneamente súbditos y soberanos, en condiciones de igualdad. Rousseau no acepta las premisas liberales respecto a la relación entre individuo y comunidad: la representación correcta de la relación política en la comunidad democrática rousseauniana no es la del equilibrio entre dos polos -individuos privados versus poder público-, sino la de la conjunción intersubjetiva en el espacio público.

Sin embargo, es preciso reconocer que en la propuesta rousseauniana, tal como se expresa literalmente en el Contrato social, hay puntos oscuros, problemáticos, que suscitan ciertas reservas.

En efecto, si bien la voluntad general es en principio inmanente al conjunto de los ciudadanos - como voluntad común construida y definida, en condiciones de libertad e igualdad, mediante la deliberación pública一, no es menos cierto que a menudo Rousseau se expresa de modo que sugiere su hipóstasis frente a los ciudadanos. La voluntad general es indestructible, y subsiste aunque nadie la exprese (CS, IV, 1); la define el interés común que encarna, más que el sufragio (II, 4), y no cabe identificarla con la voluntad de todos: fórmulas como éstas sugieren la idea de un bien público preexistente, no definido, sino descubierto mediante la deliberación y el voto.

La raíz de esta hipostatización reside probablemente en la constatación por parte de Rousseau de la diferencia entre el modelo de comunidad por él concebido y la vida política efectiva. En una comunidad como las antiguas, en la que los individuos se identificasen espontáneamente con el interés colectivo, las asambleas expresarían el bien público. Pero en las sociedades modernas, "cuando el nudo social comienza a relajarse y el Estado a debilitarse, cuando los intereses particulares comienzan a dejarse sentir, y las pequeñas sociedades a influir sobre la grande, el interés común se altera y encuentra oponentes, la unanimidad no reina ya en los votos, la voluntad general no es ya la voluntad de todos..." (OC, III, 438). Creo que es la comprobación de que los acuerdos efectivos reflejan a menudo un compromiso alejado del interés general lo que mueve a Rousseau a pensar una voluntad general hipostatizada que, como las ideas platónicas, subsiste independientemente de su realización.

$Y$ así es posible afirmar que en cada individuo hay dos voluntades, una particular y otra general, como reza el célebre pasaje (CS, I, 7) en cl que Rousseau advierte que se forzará a ser libre a quien rehúse obedecer a la voluntad general. Vale la pena detenerse un momento en él.

En clave antropológica, el pasaje puede ser leído de la manera si- 
guiente: en cada individuo hay dos clases de preferencias: sus preferencias como hombre, que corresponden a sus pasiones, y por tanto a su interés particular, y sus preferencias como ciudadano, de carácter racional, y por ello coincidentes con el interés común. Quien se atiene a sus preferencias de primer orden es, en realidad, esclavo de sus apetitos: ${ }^{25}$ ignora, o no es capaz, de seguir sus verdaderos intereses. En cambio, aquel que obedece a las leyes comunes es libre, porque éstas expresan el interés común, concordante con sus preferencias racionales. $\mathrm{Y}$ por eso puede decirse, aunque la expresión sea desafortunada, que a aquel a quien se le obliga a someterse a la ley común -mediante la coacción, a falta de mejor argumento-se le está haciendo comportarse como un ser racional, y por consiguiente libre.

Creo que el pasaje admite también una lectura directamente política. Rousseau viene a decir que, si se generalizara una actitud de atención exclusiva al interés privado - la actitud del free rider-, ello "causaría la ruina del cuerpo políticos. El gorrón actúa como alguien que no sabe o no quiere ver que la libertad de todos, incluida la suya, depende del compromiso recíproco respecto al interés común; y es preciso asegurar esta libertad incluso mediante la coacción.

Ahora bien, se trata en todo caso de una imposición coactiva de la racionalidad y el interés público; como dice Domènech ${ }_{3}{ }^{26}$ es una solución "espartana» del problema de la conjugación de los intereses privado y público: Rousseau desconfía de la capacidad de los individuos para actuar por sí mismos racionalmente, y los contiene con la ley.

Y una solución que plantea serios problemas (ligados a la hipostatización de la voluntad general). ¿Quién es el intérprete auténtico de la voluntad general? ¿Quién es capaz de decidir qué intereses responden al interés común? En último término, se plantea el problema de la supervivencia de la autonomía individual: no ya la de un interés puramente privado, sino la de los sujetos como tales, como capaces de autodeterminarse. Cabe preguntarse si cabe la disidencia de una minoría respecto a la posición mayoritaria, dada la presunción de que hay un interés general objetivo que dicha minoría quizá no ve.

Creo que la posibilidad de una respuesta satisfactoria depende del modo en que se entienda la voluntad general. Si ésta expresa un bien objetivo preexistente, toda disidencia habría de ser errónea o perversa. Pero si se interpreta la voluntad general en los términos del modelo antes descrito, sería posible afirmar simultáneamente la dimensión subjetiva y el interés común. Pues en tal caso la voluntad general no se referiría a un contenido objetivo independiente de los acuerdos reales, sino al resultado de aquellos que reúnan en grado suficiente los requisitos de libertad, igualdad, etc., mencionados. Y habría que suponer como condición todo aquello que permite a cada sujeto serlo realmente, lo que implica tanto la participación en la definición de lo que ha de entenderse en cada caso como 
interés común, como el derecho a mantener posiciones diferentes a las del resto. Al fin y al cabo, el único acuerdo necesario es, tal como observa Wellmer, ${ }^{27}$ el de mantener las condiciones del debate.

Puede pensarse que esta interpretación es anacrónica. Pero creo que $\tan$ cierto es que hay en Rousseau una tendencia a sustantivar el bien público y a negar toda subjetividad en tanto que particularidad, como que pretendió constituir una comunidad democrática fundada en la codeterminación del interés común por sujetos autónomos. $Y$ además, que no hay por qué optar entre ambas tendencias al interpretar su obra, sino examinar cómo coexisten.

\section{Los problemas de la realización de la comunidad}

Una vez formulado el modelo de la comunidad de la voluntad general, Rousseau se enfrenta al problema de si es realizable una comunidad de tales características. Pues, como hemos visto a propósito de la uparadoja de la libertad", de hecho las voluntades de los individuos que integran un pueblo no se identifican, sin más, con la voluntad general. Más bien ocurre, advierten muchos de los críticos de Rousseau, que quienes detentan el poder hacen pasar su propia voluntad por la voluntad general, y acallan toda voz disidente: ésta sería la lección del Terror jacobino. ${ }^{28}$

En otras palabras, el modelo político de la voluntad general sólo es consistente si presuponemos individuos racionales, cuya deliberación conduce infaliblemente al interés comứn, pues converge en lo objetivamente bueno. Como señaló en una ocasión Marcuse, el citoyen rousseauniano es un sujeto transformado. ${ }^{29}$ Pero el problema estriba en la reatización de la voluntad general en condiciones ordinarias. En la práctica, y dadas las condiciones e inclinaciones particularistas de los individuos, una asamblea soberana sin contrapesos bien puede adoptar decisiones irracionales, y ser manipulada o condicionada por demagogos o grupos de presión.

Ante esta dificultad, cabe concebir dos usos o aplicaciones del modelo de comunidad de la voluntad general:

a) Un uso que podemos llamar kantiano: el contrato social sería una idea de la razón, un principio regulativo que guiaría la tarea del legislador; ${ }^{30}$ como dice Philonenko, un cuarto imperativo categórico dirigido al soberano. ${ }^{31}$ Así se preservaría la integridad del modelo, al precio de convertir la idea de voluntad general en un principio meramente ético.

b) El segundo es el uso rousseauniano. Como escriben Offe y Preuss, "El contrato social puede leerse como un esfuerzo despiadado por especificar las condiciones bajo las cuales la voluntad empirica del pueblo puede aproximarse a la voluntad razonable del mismo, la volonté générale».32 Rousseau buscó la efectiva realización política de su modelo, pese a ser consciente de la extraordinaria dificultad de la tarea. 
Es precisamente esta dificultad la que empuja a Rousseau a concebir la comunidad de forma que se aleja progresivamente del modelo expuesto, y se acerca en cambio al paradigma de la comunidad tradicional: unitaria y sólidamente integrada, pero con escaso margen para el desarrollo de una subjetividad autónoma, Como bien apunta Cotta, Rousseau se mueve entre la imagen de la comunidad como Estado - que implica la cancelación de la Historia-, y la de la comunidad como Patria, basada en la veneración de las costumbres y de la comunidad antigua. ${ }^{33}$

Entre los muchos problemas que plantea la realización política de la voluntad general (gobierno, representación, regla de la mayoría, etc.) destaca el de la adecuación de las voluntades individuales a la voluntad general. ¿Cómo puede hacerse que la voluntad empírica de los ciudadanos, de hecho inclinada al interés particular, y sin competencia para detectar el interés general, pueda conocer y querer la voluntad general?

Se requeriría en primer lugar independencia en la manifestación de voluntad: lo que implica, según Rousseau, ausencia de interferencias de "sociedades parciales» que impongan como general un interés particular.

En segundo lugar sería precisa la ilustración de la voluntad popular. En primer lugar, en lo que se refiere a la información: «la voluntad general es siempre recta, pero el juicio que la guía no es siempre ilustrado (éclairé) $\times(\mathrm{OC}, \mathrm{III}, 380$ ). Es preciso discernir entre intereses inmediatos y a largo plazo, conocer los medios idóneos para los fines propuestos, etc. En suma, hay que crear un usistema de legislación": tarea compleja que parece fuera del alcance de la mayoría de los ciudadanos.

Pero, sobre todo, los ciudadanos tendrian que "conformar sus voluntades a su razón», alcanzar una disposición virtuosa que les sitúe en la perspectiva del interés público. Éste es, piensa Rousseau, el nudo gordiano de la política. ${ }^{34}$

Si los ciudadanos no son capaces de reformarse por si solos, es preciso apelar a un guía: el Legislador. Un individuo excepcional, enfrentado a la tarea de convertir al individuo en ciudadano. La cual resulta extraordinariamente difícil; máxime si, como exige Rousseau, no puede apelar a una dictadura pedagógica, sino que ha de someter sus propuestas a la ratificación de la asamblea (dada la inalienabilidad de la soberanía popular).

La situación del Legislador es paradójica: la racionalidad de sus propuestas ha de someterse al dictamen de una asamblea no ilustrada; pero para que tales propuestas fueran aceptadas por la fuerza de convicción de los argumentos sería precisa una disposición racional de los receptores: que es, precisamente, lo que se trata de crear.

Como es sabido, Rousseau resuelve la dificultad por la vía irracional de la persuasion: las normas serían presentadas como provenientes de la divinidad. Con lo que se reintroduce la denostada apariencia en la política $y$, lo que es peor, se manifiesta una profunda desconfianza en la capacidad 
de autoconstrucción de una ciudadanía democrática. La figura del legislador parece reforzar las tesis de los defensores de la teoría elitista de la democracia: puesto que la mayoría de la población no es capaz de gestionar por sí misma sus intereses, debe limitarse a ratificar con su voto la actuación de los expertos que rigen la vida pública.

Ciertamente, el problema de la formación de una disposición cívica es tan crucial para la democracia como difícil de resolver. Y Rousseau da buena prueba de ello en el mismo Contrato social: oscila entre la desesperanza respecto a la posibilidad de construir una comunidad en las sociedades modernas, y los intentos de recuperación del espíritu patriótico de la Antigüedad.

Los capítulos que siguen al dedicado al Legislador exponen las condiciones que debería reunir el pueblo, para que fuera eficaz la acción de aquél. Además de condiciones demográficas, geográficas, históricas, etc., sería preciso que las mores del pueblo en cuestión prestaran una base sobre la que pudiera arraigar la legislación. Pues más importante que las normas jurídicas es otra ley "que no se graba sobre el mármol ni sobre el bronce, sino en los corazones de los ciudadanos; que forma la verdadera constitución del Estado [...]. Hablo de las costumbres [moeurs], de los usos [coutumes], y sobre todo de la opinión" (CS, II, 12; OC, III, 394). Se expresa aquí (como en otros lugares: véase en particular la Carta a D'Alembert) el ideal de una comunidad en la que la vinculación de los individuos arraiga en lazos anteriores a la institucionalización jurídico-política, y en la que una opinión homogénea, en virtud de la comunidad de vida y tradiciones, es el más eficaz regulador de la moralidad de las acciones.

El problema es que tal comunidad exige un tipo de integración social difícilmente esperable en las sociedades modernas complejas. Las primeras páginas del libro $\mathrm{IV}$ de El contrato social esbozan una sociedad en la que «el bien común se muestra por doquier con evidencia, y no exige más que sentido común para ser percibidon (OC, II, 437), de manera que son superfluas las usutilezas políticas»: deliberaciones y votaciones son innecesarias cuando hay una concordancia espontánea, basada en las convicciones adquiridas y compartidas sobre la base de la tradición. Pero sociedades de este tipo son ya excepcionales: los individuos modernos no reconocen un bien común, ni se vinculan afectivamente a una patria: prefieren pagar a representantes y mercenarios, constata amargamente Rousseau (cf. CS, III, 15). El desarrollo de la individualidad imposibilita la identificación inmediata con la comunidad.

Ante esta situación caben diversas respuestas. En primer lugar, negar que tenga sentido la idea de bien público - y la idea de comunidad, a fin de cuentas-; lo único real serian los intereses particulares, entre los cuales habría que buscar un equilibrio satisfactorio.

Tal vez pudiera tambiên ensayarse la reconstrucción de la comunidad 
como intersubjetividad, en la dirección arriba expuesta: pero ya hemos visto las dificultades a que se enfrentaría tal proyecto.

Por último, cabe intentar la recuperación del espíritu comunitario en la sociedad moderna, mediante el recurso a instrumentos de vinculación afectiva a la colectividad. Es la propuesta de los neoconservadores actuales, y también parece inclinarse por ella, en último término, el propio Rousseau.

Pues El contrato social concluye, sintomáticamente, con el capítulo dedicado a la religión civil. $\mathrm{Y}$ lo que a fin de cuentas plantea es cómo establecer un vínculo comunitario en una sociedad que ha perdido los lazos de integración vivenciales y religiosos propios de las sociedades premodernas, y que sin embargo no es capaz de cohesionar a sus miembros mediante la apelación desnuda a lo racional.

La nostalgia de la simbiosis entre religión y patria que se dio en la Antigüedad no le impide a Rousseau reconocer que en el contexto europeo moderno la religión patria sería imposible - y aun indeseable por su exclusivismo. Pero al mismo tiempo, duda de la viabilidad de una integración social fundada únicamente en las leyes: la comunidad política real precisa de una vinculación que, a juicio de Rousseau, no puede ser meramente pensada, dictada por el razonamiento, sino vivida, sentida afectivamente.

Así se entiende su oposición al cosmopolitismo, expresada en numerosos lugares de sus obras, como éste del Manuscrito de Ginebra:

Concebimos la sociedad general según nuestras sociedades particulares, la institución de las pequeñas repúblicas nos hace pensar en la grande, y no comenzamos propiamente a convertimos en hombres sino después de haber sido ciudadanos. Por donde se ve qué hay que pensar de esos pretendidos cosmopolitas, que al justificar su amor hacia la patria por su amor hacia el género humano, se jactan de amar a todo el mundo para tener el derecho de no amar a nadie [OC, III, 287].

El cosmopolitismo implica la relativización de lo patrio, el dístanciamiento respecto al propio ethos: es la actitud propia del espíritu ilustrado, que se atiene al universalismo de la razón. Y serían admirables, reconoce Rousseau, las almas cosmopolitas capaces de sabrazar a todo el género humano en su benevolencia" (OC, III, 178); pero, de hecho, el cosmopolitismo es un universalismo abstracto, separado de la comunidad real.

La comunidad ha de realizarse como patria, lo que requiere una adhesión más fuerte que la que proporciona el espíritu individualista de las sociedades modemas. Por ello propone Rousseau el establecimiento de una religion civil, que garantice los «sentimientos de sociabilidad": un mínimo de convicciones compartidas necesario para apuntalar el orden juridico-político, a falta de la identificación espontánea del patriotismo republicano.

Sin duda, el problema al que responde esta propuesta es de plena actualidad. Baste recordar el diagnóstico de Bell respecto a la crisis de la 
sociedad contemporánea - una carencia de sentido generalizada, manifiesta en el hedonismo, la búsqueda de gratificación inmediata y la falta de disposición para contribuir al bien público-, 35 y la solución que apunta (igual que Berger o Novak): el retorno a la religión, sustrato último del sistema cultural occidental.

$\mathrm{Y}$ en esta vía pueden situarse las tendencias a la sacralización de lo profano que, como ha hecho notar, entre otros, S. Giner, ${ }^{36}$ se está produciendo en las sociedades avanzadas: toda una serie de rituales y liturgias cívicas que tratan de dotar de identidad y cohesión a colectividades socialmente heterogéneas. Y que refuerzan el vínculo social con más eficacia que la coacción o que las consideraciones racionales.

Pero el sentimiento cuasirreligioso de pertenencia, la instauración afectiva de la identidad colectiva, tiene su contrapartida. Implica, como el mismo Giner señala, «suspender discernimiento, escepticismo y distanciam. ${ }^{37} \mathrm{El}$ sangriento reverdecer de los nacionalismos en Europa muestra los riesgos y consecuencias de seguir esta vía.

Rousseau sintió aún la tentación de refugiarse en una comunidad protectora, y así resguardarse del desgarramiento de la sociedad moderna. Pero hoy, definitivamente a la intemperie, no parece haber otra solución que intentar conjugar comunidad y autonomía, por difícil que resulte, y basar el vínculo social, no en la tierra, la sangre y el pasado, sino en la solidaridad construida reflexivamente.

\section{NOTAS}

1. Desde Constant, De Maistre o Marx, a Berlin, Fetscher, Colletti o Starobinski, Rousseau ha sido visto, ya como un pensador liberal, ya como el creador del totalitarismo moderno; como un revolucionario innovador o un reaccionario nostálgico.

2. En *Das Problem Jean-Jacques Rousseau", Archiv für Geschichte der Philosophie, tomo XII (1932), pp. 177-213 y 479.515 .

3. Puede verse al respecto, entre otros, el reciente libro de $C$. Thiebaut, Los límiter de la comunidad, Madrid, Centro de Estudios Constitucionales, 1992.

4. Cf. J. Muguerza, "Más allá del contrato social (Venturas y desventuras de la ética comunicativa)n, en Desde la perplejidad, Madrid, FCE, 1990, pp. 255-376.

5. Así, p. ej.. M.J. Villavende (Rousseau y el pensamiento de las Luces, Madrid. Tecnos, 1988) cree que el deseo inconfesable de Rousseau es detener la marcha de la Historia, preservar a los pueblos salvajes de los males de la civilización (cf. p. 60). za, 1988 .

6. Cf. H. Béjar, El ámbito fntimo. Privacidod, individualismo y modernidad, Madrid, Alian-

7. Las obras de Rousseau se citan, como es habitual, por la edición de B. Gagnebin y $M$. Raymond de París, Gallimard, 1959. (Me referiré a esta edición con las siglas OC, y a $E l$ contrato social dentro de esta edición con las siglas CS.)

8. Véase, p. ej., el poema filosófico «Le Mondain".

9. CE. D. Leduc-Fayette, Jear-Jacques Rousseau et le mythe de lAntiquite, Paris, Vrin, 1974.

10. Así lo han visto, entre otros, Cassirer (op. cit.) y Vaughan (The Political Writings of J.J. Rousseau, Cambridge, 1915). 
11. Eso es al menos lo que sostiene V. Goldschmidt en Anthropologie et politique: les principes du système de Rousseuu, París, Vrin, 1974.

12. Asi, p. ej. Colletti («Rousseau, critico della societa civile», en Ideologia e società, Bari. Laterza, 1975) le neconoce el mérito de haber esbozado *en condiciones históricas todavía inmaduras [...] los primeros y fundamentales capítulos de una crítica de la sociedad burguesa modemas (p. 237).

13. Cf. J. Starobinski, J.J. Rousseau: In transparencia y et obstaculo, Madrid, Taurus, 1983; así como S. Cotta, "Rousseau o dell'insufficienza della politican, en Rousseau selon Jean-Jacques. Actas del Coloquio de Roma (mayo 1978), Florencia, Ufficio Attivita Culturali dell'Istituto della Enciclopedia Italiana, 1979 , pp. $41-49$.

14. Véanse las líneas finales de la nota 9." del Discurso sobre la desigualdad (OC, III, 207-208), asi como el libro III del Emilio (OC, IV, pp. 467 y 483 ).

15. Ak. VIII, pp, 107-124.

16. En Jean-Jacques Rousseau et la pensée du matheur, París, Vrin, 1984.

17. Véase el $\$ 258$ de los Principios de la filosofia del derecho.

18. Cf. Roussedu y Marx, Barcelona, Martínez Roca, 1969, p. 20.

19. Véase «Problemas de legitimación en el Estado modemo», en La reconstrucción del materiatismo historico, Madrid, Taurus, 1981, p. 250.

20. Cf. R. Derathe, Jean-Jacques Rousseau et la science politique de son tenps, París, Vrin, $1970^{2}$.

21. El término se halla literalmente en El contrato social, I, 7 (OC, III, p. 362).

22. Problemas de legitimación del capitalismo tardio, Buenos Aires, Amorrortu, 1975, p. 131.

23. Cf., p. ej., J.B. Talmon, Los origenes de la democracia totaliiaria, México, Aguilar, 1956, p. 66 .

24. Cf. I. Berlin, Cuatro ensayos sobre la libertad, Madrid, Alianza, 1988, p. 234.

25. Vease al respecto el análisis de A. Domenech en De la ética a la poltíca, Barcelona, Crítica, 1989 , pp. 270-279.

26. Ibidem, p. 270.

27. CE. A. Wellmer, "Modelos de libertad en el mundo moderno", en C. Thiebaut (ed.), La herencia ética de la llustracion, Barcelona, Critica, 1991, pp. 104-135.

28. Cf. L. Jaume, El jacobinismo y el Estado modemo, Madrid, Instituto de España / Espasa Calpe, 1990.

29. Recogido en J. Habermas, "Diálogo con Herbert Mancusew, en Perfiles filosófico-poltitcos, Madrid, Taurus, 1975, p. 263.

30. Cf. I. Kant, Uber den Gemeinspruch..., Ak. VIII, p. 297.

31. Cf. A. Philonenko, Theorie et praxis dans la pensée morale de Kant et de Fichte en 1793. Paris, Vrin, 1968.

32. C. Offe y U. Preuss, aInstituciones democráticas y recursos morales», Isegoria (Madrid), n." 2 (1990), p. 55.

33. Art. cit., p. 46.

34. "¿Cómo es posible -escribe Rousseau en el Manuscrito de Ginebra- que un individuo pueda trascender su inter's particular y situarse en el purto de vista del intenés general, imponiéndosc así obligaciones cuya conexión con el propio interes no percibe? (OC, III, p. 286).

35. Cf. D. Bell, Las contradicciones culturales del capitatismo, Madrid, Alianza, 1977, p. 39.

36. Cf. S. Giner, "Religión civil», Claves de Razón Práctica (Madrid), n." 11 (abríl 1991), p. 16.

37. Ibidem. 